Supplement of Hydrol. Earth Syst. Sci., 24, 1527-1542, 2020

https://doi.org/10.5194/hess-24-1527-2020-supplement

(c) Author(s) 2020. This work is distributed under

the Creative Commons Attribution 4.0 License.

(c) (1)
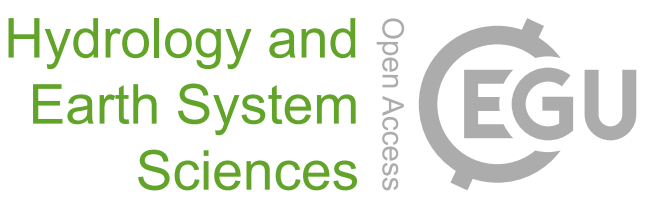

Supplement of

\title{
The role of liquid water percolation representation in estimating snow water equivalent in a Mediterranean mountain region (Mount Lebanon)
}

\author{
Abbas Fayad and Simon Gascoin \\ Correspondence to: Abbas Fayad (abbas.fayad@usask.ca)
}

The copyright of individual parts of the supplement might differ from the CC BY 4.0 License. 


\section{Supplement}
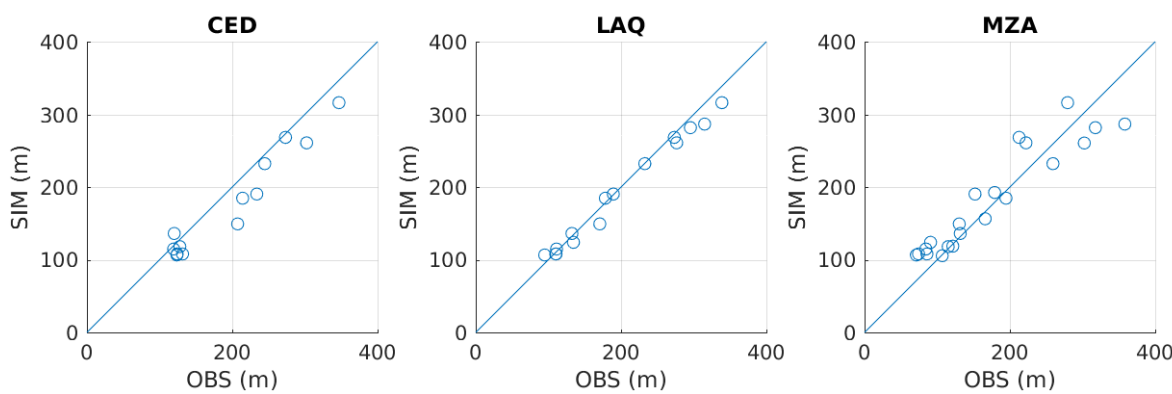

Incoming shortwave $\left(\mathrm{W} / \mathrm{m}^{2}\right)$
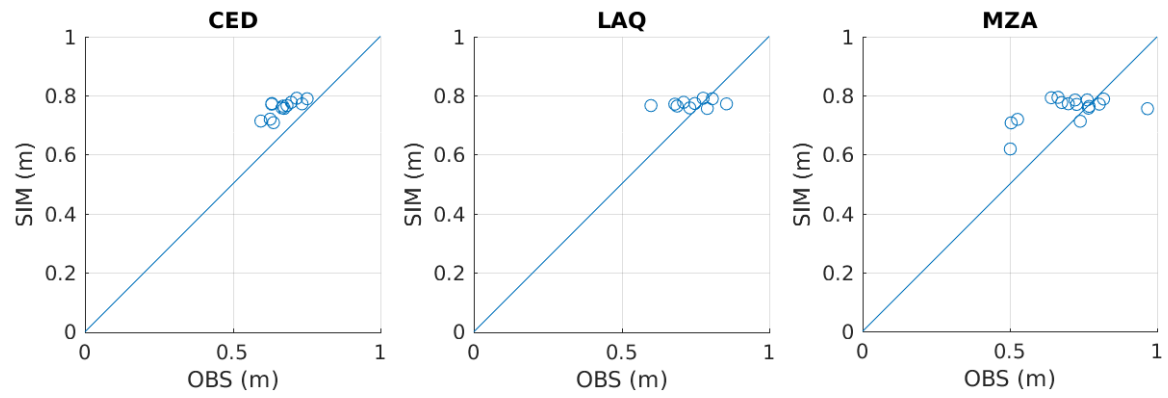

Snow albedo

Figure S1. Scatterplots of observed vs. modelled monthly incoming shortwave radiation and snow albedo.

Figure S1 compares the monthly observed and modelled shortwave radiation and snow albedo at the three AWS. Here the Pflug et al. (2019) model was used.The incoming shortwave is well simulated with correlation coefficients ranging between 0.94 and 0.99 and RMSE ranging between $13 \mathrm{~W} \mathrm{~m}^{-2}$ (LAQ) and $32 \mathrm{~W} \mathrm{~m}^{-2}$ (MZA). The snow albedo variability is less accurately captured but the RMSE remains acceptable with 0.086, 0.074, and 0.096 at CED, LAQ, and MZA respectively. 